Journal of Luminescence 35 (1986) 163-170

North-Holland, Amsterdam

\title{
PHOTOLUMINESCENCE STUDIES OF LAYERED TRANSITION METAL PHOSPHORUS CHALCOGENIDES AND THEIR PYRIDINE INTERCALATION COMPOUNDS
}

\author{
D.A. CLEARY, A.H. FRANCIS \\ Department of Chemistry, The University of Michigan, Ann Arbor, Michigan 48109, U.S.A. \\ E. LIFSHITZ \\ Weizmann Institute of Science, Rehovot, Israel \\ Received 13 January 1986 \\ Accepted 6 March 1986
}

\begin{abstract}
Ultraviolet photoexcitation of $\mathrm{Cd}_{2} \mathrm{P}_{2} \mathrm{~S}_{6}$ and $\mathrm{Zn}_{2} \mathrm{P}_{2} \mathrm{~S}_{6}$ single crystals produces a characteristic photoluminescence between 2.5 and $1.5 \mathrm{eV}$. $\mathrm{Mn}_{2} \mathrm{P}_{2} \mathrm{~S}_{6}$ exhibits only low energy emission due to transitions between localized d-orbital states. These results are consistent with the electronic band structure model for transition metal phosphorus chalcogenides with the general chemical formula $\mathrm{M}_{2} \mathrm{P}_{2} \mathrm{X}_{6}(\mathrm{Cd}, \mathrm{Zn}, \mathrm{Mg}, \mathrm{Mn}, \mathrm{X}=$ sulfur or selenium), which predicts highly localized states associated with the transition metal $\mathrm{d}$ orbitals and delocalized, band-like states derived from sulfur and phosphorus orbitals.

When pyridine containing a small amount of water is intercalated into $\mathrm{Cd}_{2} \mathrm{P}_{2} \mathrm{~S}_{6}$, the excitation and the photoluminescence spectra are changed substantially. The photoluminescence intensity increases approximately tenfold and the position of the excitation edge is shifted to lower energy by $0.5 \mathrm{eV}$. Intercalation with anhydrous pyridine does not affect either the excitation spectrum or the photoluminescence spectrum of the host lattice.
\end{abstract}

\section{Introduction}

$\mathrm{Mg}_{2} \mathrm{P}_{2} \mathrm{~S}_{6}, \mathrm{Mn}_{2} \mathrm{P}_{2} \mathrm{~S}_{6}, \mathrm{Zn}_{2} \mathrm{P}_{2} \mathrm{~S}_{6}, \mathrm{Cd}_{2} \mathrm{P}_{2} \mathrm{~S}_{6}$ and $\mathrm{Cd}_{2} \mathrm{P}_{2} \mathrm{Se}_{6}$ are layered compounds with similar crystal structures. The transition metal atoms occupy lattice planes and are octahedrally coordinated by chalcogen atoms. As reported in ref. $[1,2]$ the phosphorus is covalently bonded to form $\mathrm{P}_{2}$ pairs which occupy sites in the plane of the transition metal ions and are covalently bonded to an octahedral arrangement of sulfur atoms forming a $\mathrm{P}_{2} \mathrm{~S}_{6}$ trigonal bipyramidal structure. Thus, the transition metal atoms (and $P_{2}$ pairs) occupy planes 'sandwiched' between planes of chalcogen atoms. The macroscopic structure is built by stacking the sandwich repeat units along the crystallographic $c$-axis.

These materials are particularly interesting because the weak Van der Waals interactions between adjacent chalcogen atom planes permit easy intercalation of guest molecules into the intersti- tial space, or Van der Waals gap (VWG), between repeat units. Previous spectroscopic studies of intercalated layered lattices have shown that intercalation changes the interactions between neighboring layers and frequently results in a broadening of the electronic bands so that the band edges extend into the host lattice band gap [3]. These changes may be slight and therefore difficult to detect by direct absorption spectroscopy. Luminescence and luminescence excitation spectroscopy preferentially sample states near the band edges which are sensitive to intercalation and thus these techniques may be useful in the study of structural changes accompanying lattice intercalation.

Band model for $M_{2} P_{2} X_{6}$ lattices

Khumalo and Hughes [4] proposed the electronic band model for the $\mathrm{M}_{2} \mathrm{P}_{2} \mathrm{X}_{6}$ layer compounds illustrated in fig. 1 . The model assumes

0022-2313/86/\$03.50 ( Elsevier Science Publishers B.V.

(North-Holland Physics Publishing Division) 


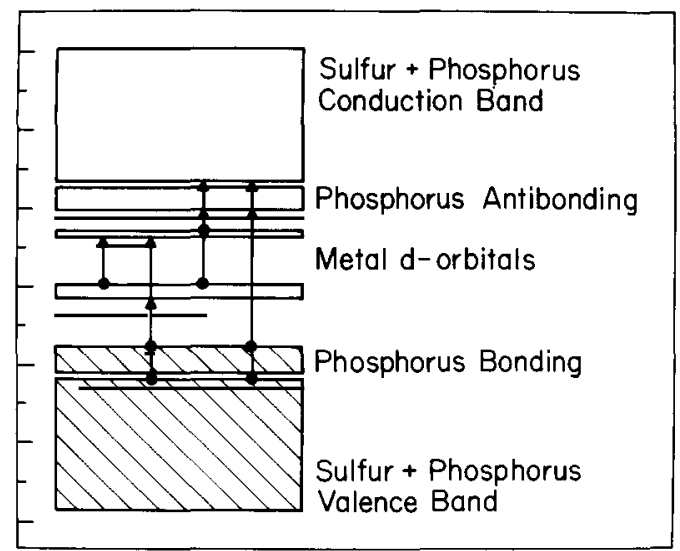

Fig. 1. Energy band model for the $\mathrm{M}_{2} \mathrm{P}_{2} \mathrm{X}_{6}$ lattices proposed by Khumalo and Hughes [4].

the complete transfer of two metal atom electrons to the $\mathrm{P}_{2} \mathrm{~S}_{6}$ moiety to form $\left(\mathrm{M}^{2+}\right)_{2}\left(\mathrm{P}_{2} \mathrm{~S}_{6}^{4-}\right)$. In the ionic compound, the transition metal ions are in a high-spin, divalent oxidation state, in the nearly octahedral field of six chalcogen atoms. Since the spatial extent of the d orbitals is relatively small, the $\mathrm{d}$ orbitals on nearest-neighboring ions overlap only slightly and thus form very narrow bands.

The $\mathrm{P}-\mathrm{P}$ bond of $\mathrm{P}_{2} \mathrm{~S}_{6}$ produces two narrow electronic bands, one bonding with an energy slightly above the valence band, and the second, antibonding with an energy just below the conduction band. Phosphorus and sulfur contribute $3 \mathrm{p}_{x}, 3 \mathrm{p}_{y}$ and $3 \mathrm{~s}$ orbitals which form the main valence and conduction bands. The band structure model assumes that there is little mixing of the metal $d$ orbitals with the sulfur $p$ orbitals in both the valence and conduction band states.

The first-row transition metal $\mathrm{M}_{2} \mathrm{P}_{2} \mathrm{~S}_{6}$ compounds should have essentially identical spectra, except for those features arising from the metal 3d levels. Four different types of electronic transitions may occur in these materials. With reference to the energy band scheme in fig. 1, they are, in order of increasing energy:

(1) Weak, localized $\mathrm{d} \leftarrow \mathrm{d}$ transitions between $0.5-4 \mathrm{eV}$, depending upon the transition metal.

(2) Charge transfer transitions in the range $2-3 \mathrm{eV}$ from the sulfur and phosphorus valence bands to transition metal $3 \mathrm{~d}$ states, designated $\mathrm{d} \leftarrow \mathrm{V}$ transitions.
(3) Charge-transfer transitions with energies below $4 \mathrm{eV}$ from the localized $3 \mathrm{~d}$ states to phosphorus and sulfur conduction band states, designated $\mathrm{C} \leftarrow \mathrm{d}$ transitions.

(4) Interband transitions $>3 \mathrm{eV}$ from the valence to the conduction bands, designated $\mathrm{C} \leftarrow \mathrm{V}$ transitions.

The absorption edge in semiconductors without transition metal elements corresponds to excitation across the band gap between the valence and conduction bands of the material. The analogous excitation in the $\mathrm{M}_{2} \mathrm{P}_{2} \mathrm{X}_{6}$ lattices corresponds to the $\mathrm{C} \leftarrow \mathrm{V}$ transition of the $\mathrm{P}_{2}$ pair (see fig. 1). However, in the presence of partially filled $d$ orbitals, the low-energy absorption edge is not a measure of the gap between delocalized, excitonic valence and conduction bands, but rather the crystal field splitting of localized transition metal states which lie within the band gap. This situation complicates band-gap measurements in these materials by optical spectroscopy.

Brec et al. [5] recorded the single-crystal optical absorption spectra of $\mathrm{Ni}_{2} \mathrm{P}_{2} \mathrm{~S}_{6}, \mathrm{Fe}_{2} \mathrm{P}_{2} \mathrm{~S}_{6}, \mathrm{Mn}_{2} \mathrm{P}_{2} \mathrm{~S}_{6}$, $\mathrm{Mn}_{2} \mathrm{P}_{2} \mathrm{Se}_{6}, \mathrm{Cd}_{2} \mathrm{P}_{2} \mathrm{~S}_{6}$ and $\mathrm{Cd}_{2} \mathrm{P}_{2} \mathrm{Se}_{6}$ in the region of the absorption edge, $0.5-3.5 \mathrm{eV}$. They reported optical band gaps determined from the first inflection in the absorption curves, noting that the presence of $\mathrm{d} \leftarrow \mathrm{d}$ transitions near the absorption edge made accurate measurements difficult. Audiere et al. [6] recorded weak continuous absorption below $3.5 \mathrm{eV}$ in $\mathrm{Cd}_{2} \mathrm{P}_{2} \mathrm{~S}_{6}$, however, these results appear to be in conflict with our measurements and those reported by Brec et al. [5].

The reflectance spectra of $\mathrm{Ni}_{2} \mathrm{P}_{2} \mathrm{~S}_{6}, \mathrm{Mn}_{2} \mathrm{P}_{2} \mathrm{~S}_{6}$ and $\mathrm{Fe}_{2} \mathrm{P}_{2} \mathrm{~S}_{6}$ were investigated by Khumalo and Hughes [4]. These spectra were found to be almost identical between $4-14 \mathrm{eV}$, indicating that above $4 \mathrm{eV}$ the spectra are determined principally by the electronic structure of the $\mathrm{P}_{2} \mathrm{~S}_{6}$ group and consist predominately of $\mathrm{C} \leftarrow \mathrm{V}$ transitions.

Piacentini et al. [7] examined the electronic transitions and XPS of $\mathrm{Ni}_{2} \mathrm{P}_{2} \mathrm{~S}_{6}$ in the energy range $1-25 \mathrm{eV}$. The optical spectrum exhibits a weak absorption peak at $1.6 \mathrm{eV}$ assigned to the localized $\mathrm{d} \leftarrow \mathrm{d}$ transition. The first strong band in the $\mathrm{Ni}_{2} \mathrm{P}_{2} \mathrm{~S}_{6}$ spectrum occurs at $2.2 \mathrm{eV}$. This band is assigned to a $\mathrm{d} \leftarrow \mathrm{V}$ charge-transfer transition from sulfur valence bands to the empty $\mathrm{Ni} 3 \mathrm{~d}$ 
states. Several bands appear in the optical spectrum to higher energy (between $3-4.5 \mathrm{eV}$ ). The bands centered at $3.7 \mathrm{eV}$ were attributed to the anti-bonding $\leftarrow$ bonding, $\mathrm{C} \leftarrow \mathrm{V}$ excitation of the $\mathrm{P}_{2}$ bond. This transition is expected to be located at approximately the same energy in other $\mathrm{M}_{2} \mathrm{P}_{2} \mathrm{X}_{6}$ lattices [7].

The weak $1.1 \mathrm{eV}$ peak in $\mathrm{Fe}_{2} \mathrm{P}_{2} \mathrm{~S}_{6}$ probably arises from the $3 \mathrm{~d}$ states of $\mathrm{Fe}[8,9]$. The bands observed at 1.75 and $2.14 \mathrm{eV}$ may also be of this nature. Several low-energy bands in the absorption spectrum of $\mathrm{Fe}_{2} \mathrm{P}_{2} \mathrm{~S}_{6}$ that do not have counterparts in the $\mathrm{Zn}_{2} \mathrm{P}_{2} \mathrm{~S}_{6}$ spectrum, have been assigned to charge transfer transitions from the $\mathrm{P}-\mathrm{S}$ orbitals to the empty $\mathrm{Fe} 3 \mathrm{~d}$ states.

Boerio-Goates et al. [10] have analyzed the photoluminescence and optical excitation spectrum of $\mathrm{Mn}_{2} \mathrm{P}_{2} \mathrm{~S}_{6}$ and $\mathrm{Mn}^{++}$centers in $\mathrm{Cd}_{2} \mathrm{P}_{2} \mathrm{~S}_{6}$ in the energy range $1-6 \mathrm{eV}$. The excitation spectrum below $3 \mathrm{eV}$ exhibits only $\mathrm{d} \leftarrow \mathrm{d}$ transitions. A strong excitation edge (corresponding to the onset of photoconductivity in $\mathrm{Mn}_{2} \mathrm{P}_{2} \mathrm{~S}_{6}$ ), was observed in both compounds at about $3 \mathrm{eV}$. The results of previous spectroscopic studies are correllated and summarized in table 1 . The question marks in table 1 indicate that the transition has not been observed and solid line entries indicate that a transition is not appropriate because of the d-orbital configuration.

Intercalated $M_{2} P_{2} X_{6}$ lattices

Brec et al. [5] studied changes in the absorption spectra of $\mathrm{Ni}_{2} \mathrm{P}_{2} \mathrm{~S}_{6}, \mathrm{Fe}_{2} \mathrm{P}_{2} \mathrm{Se}_{6}$ and $\mathrm{Fe}_{2} \mathrm{P}_{2} \mathrm{~S}_{6}$ in the
$0.37-2.49 \mathrm{eV}$ range upon electrochemical intercalation of lithium. The dramatic increase in the absorbance over the entire range examined was attributed to an increase in the number of free electrons. In contrast, the absorption spectrum of $\mathrm{Ni}_{2} \mathrm{P}_{2} \mathrm{~S}_{6}$ is little changed by metallocene intercalation [9]. Shifts in the energies of the $d \leftarrow d$ transitions suggest changes in the strength of the crystal field at the metal ion.

Finally, very few optical emission studies of intercalated lattices have been reported and none for the intercalated $\mathrm{M}_{2} \mathrm{P}_{2} \mathrm{X}_{6}$ lattices.

\section{Experimental}

\section{Sample preparation}

Single crystals of the $\mathrm{M}_{2} \mathrm{P}_{2} \mathrm{X}_{6}$ transition metal phosphorus sulfides ( $M=\mathrm{Zn}, \mathrm{Cd}, \mathrm{Mg}, \mathrm{Mn}$ ) were synthesized by procedures described in detail elsewhere [1,2,11]. $\mathrm{Cd}_{2} \mathrm{P}_{2} \mathrm{Se}_{6}$ was synthesized from the metal, $\mathrm{P}$ and Se. These components were thoroughly mixed by grinding the stoichiometric amounts together. A one gram charge of the mixture was placed in an $8 \mathrm{~cm} \times 1 \mathrm{~cm}$ diameter Vycor tube together with approximately $10 \mathrm{mg}$ of crystalline iodine. The tube was evacuated to less than $10^{-4}$ Torr, sealed-off and heated to $700^{\circ} \mathrm{C}$ for 75 h.

$\mathrm{Cd}_{2} \mathrm{P}_{2} \mathrm{~S}_{6}$ (pyridine) ${ }_{0.5}$ was prepared by heating single crystals of $\mathrm{Cd}_{2} \mathrm{P}_{2} \mathrm{~S}_{6}$ in pyridine to $77^{\circ} \mathrm{C}$ for $1-3 \mathrm{~d}$ in a sealed glass ampule. The amount of

Tabel 1

Electronic transitions of $\mathrm{M}_{2} \mathrm{P}_{2} \mathrm{~S}_{6}$ lattices (energies in $\mathrm{eV}$ )

\begin{tabular}{|c|c|c|c|c|c|c|c|}
\hline & $\mathrm{Mg}_{2} \mathrm{P}_{2} \mathrm{~S}_{6}$ & $\mathrm{Mn}_{2} \mathrm{P}_{2} \mathrm{~S}_{6}$ & $\mathrm{Fe}_{2} \mathrm{P}_{2} \mathrm{~S}_{6}$ & $\mathrm{Ni}_{2} \mathrm{P}_{2} \mathrm{~S}_{6}$ & $\mathrm{Cd}_{2} \mathrm{P}_{2} \mathrm{~S}_{6}$ & $\mathrm{Zn}_{2} \mathrm{P}_{2} \mathrm{~S}_{6}$ & $\mathrm{GaS}$ \\
\hline $\mathrm{d} \leftrightarrow \mathrm{d}$ & - & $1.92^{\mathrm{a}, \mathrm{b}}$ & $1.1^{\mathrm{d}}$ & $1.0^{\mathrm{c}}$ & - & - & - \\
\hline $\mathrm{d} \leftrightarrow \mathrm{d}$ & & $2.48^{\mathrm{a.b}}$ & $1.75^{\mathrm{d}}$ & $1.6^{\mathrm{c}}$ & & & \\
\hline $\mathrm{d} \leftrightarrow \mathrm{d}$ & & $2.69^{a . b}$ & $2.14^{d}$ & & & & \\
\hline $\mathrm{d} \leftrightarrow \mathrm{V}$ & - & $?$ & $?$ & $2.2^{\mathrm{c} . \mathrm{d}}$ & - & - & - \\
\hline$C \leftrightarrow V$ & & $3.0^{\text {a.e }}$ & $?$ & & $3.0^{\mathrm{a}}$ & $3.0^{\mathrm{a}}$ & $3.01^{\mathrm{d}}$ \\
\hline $\mathrm{C} \leftrightarrow \mathrm{V}$ & $3.35^{b}$ & $3.5^{b}$ & & $3.3^{\mathrm{c.d}}$ & $3.4^{b}$ & $3.4^{\mathrm{e}}$ & \\
\hline $\mathrm{C} \leftrightarrow \mathrm{V}$ & & & & & $3.5^{\mathrm{e}}$ & $3.8^{\mathrm{d}}$ & \\
\hline
\end{tabular}

a Photoexcitation, this study.

b Transmission, this study.

c Transmission, ref. [7].

d Transmission, ref. [8].

e Transmission, ref. [5]. 
intercalated pyridine was determined from TGA measurements and chemical analysis. Thermal gravimetric analysis (TGA) was done on a DuPont Instruments Model R90 Thermal Analyzer equipped with a Model 951 Thermogravimetric Analyzer. X-ray diffraction data were collected using both a Phillips automatic powder diffractometer and a Debye-Scherrer camera using $\mathrm{CuK}_{\alpha} \mathrm{X}$-ray radiation. The observed basal plane expansions were in agreement with previously published values for this compound.

\section{Electronic spectra}

Excitation and photoluminescence spectra were recorded using single crystals of high optical quality, grown from the vapor phase, which exhibited well-defined morphology. The crystals were cooled to temperatures between $77 \mathrm{~K}$ and $4 \mathrm{~K}$ using a Janis 10DT cryostat. Sample photoluminescence was excited with the output from a high-pressure 1 $\mathrm{kW}$ xenon arc lamp, dispersed with a $\frac{1}{2} \mathrm{~m}$ monochromater (bandpass $0.01 \mathrm{eV}$ or less). The crystal photoluminescence was filtered with either a Corning 3-70, 3-67, or 2-62 glass filter, dispersed with a $1 \mathrm{~m}$ Interactive Technology monochromator (bandpass $\sim 0.02 \mathrm{eV}$ ), and detected with a cooled RCA 7102 photomultiplier.

\section{Results}

At temperatures between $77 \mathrm{~K}$ and $4 \mathrm{~K}$, the photoluminescence spectrum of $\mathrm{Cd}_{2} \mathrm{P}_{2} \mathrm{~S}_{6}$ consists of three bands. Each may be separately excited by irradiation at a different energy as illustrated in fig. 2 for the spectra recorded at $77 \mathrm{~K}$. Excitation at $2.95 \mathrm{eV}$ produces the $2.11 \mathrm{eV}$ photoluminescence peak (fig. 2b); excitation peaks at $3.55 \mathrm{eV}$ and $3.16 \mathrm{eV}$ produce a photoluminescence peak at $2.41 \mathrm{eV}$ (fig. 2a) and excitation at $3.46 \mathrm{eV}$ stimulates the $1.5 \mathrm{eV}$ photoluminescence band (fig. 2c). The relaltive intensity of the three emission bands varies reproducibly with temperature and somewhat from sample to sample and also depends slightly upon the methods of crystal preparation. The emission spectrum of $\mathrm{Zn}_{2} \mathrm{P}_{2} \mathrm{~S}_{6}$ is qualitatively similar to that of $\mathrm{Cd}_{2} \mathrm{P}_{2} \mathrm{~S}_{6}$ and is not shown.

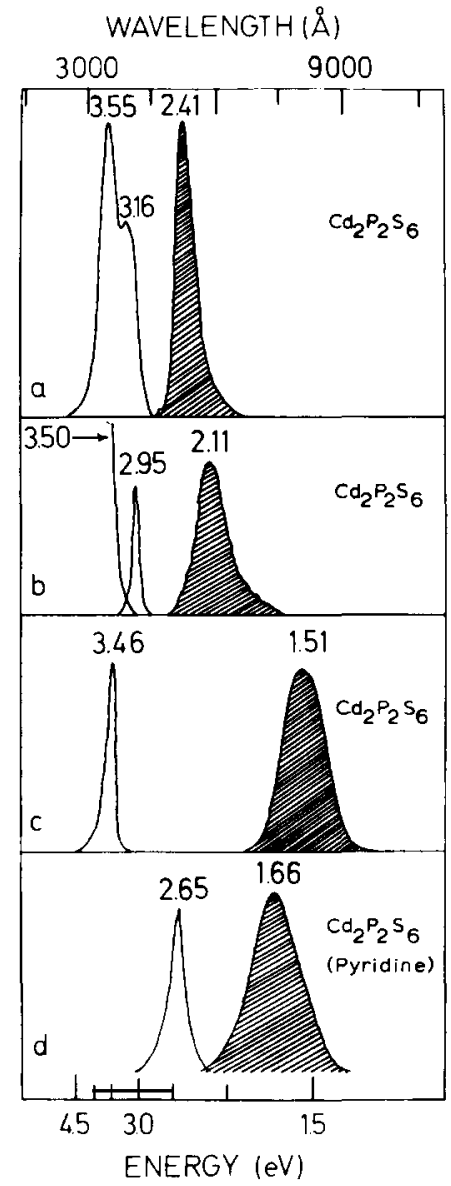

Fig. 2. Photoluminescence and photoexcitation excitation spectra of $\mathrm{Cd}_{2} \mathrm{P}_{2} \mathrm{~S}_{6}$ and its pyridine intercalation compound recorded at $77 \mathrm{~K}$. (a) $3.55 \mathrm{eV}$ and $3.16 \mathrm{eV}$ excitation peaks and the associated 2.41 photoluminescence band. (b) Absorption edge of $\mathrm{Cd}_{2} \mathrm{P}_{2} \mathrm{~S}_{6}$ is shown together with the $2.95 \mathrm{eV}$ excitation peak and the associated photoluminescence band. (c) $3.46 \mathrm{eV}$ excitation peak and the associated $1.51 \mathrm{eV}$ photoluminescence band. (d) Excitation spectrum and photoluminescence spectrum of the pyridine/water intercalated lattice.

Only a single photoluminescence band at $1.37 \mathrm{eV}$ is observed from $\mathrm{Mn}_{2} \mathrm{P}_{2} \mathrm{~S}_{6}$. When the photoluminescence is monitored, the excitation spectrum shown in fig. 3 is obtained.

The emission spectrum of $\mathrm{Cd}_{2} \mathrm{P}_{2} \mathrm{Se}_{6}$ exhibits two bands (1.86 eV and $1.37 \mathrm{eV})$ and is similar in general appearance to those of the sulfide lattices, but shifted to lower energy.

The absorption edge of $\mathrm{Cd}_{2} \mathrm{P}_{2} \mathrm{~S}_{6}$ obtained with light normally incident to the basal plane is shown 


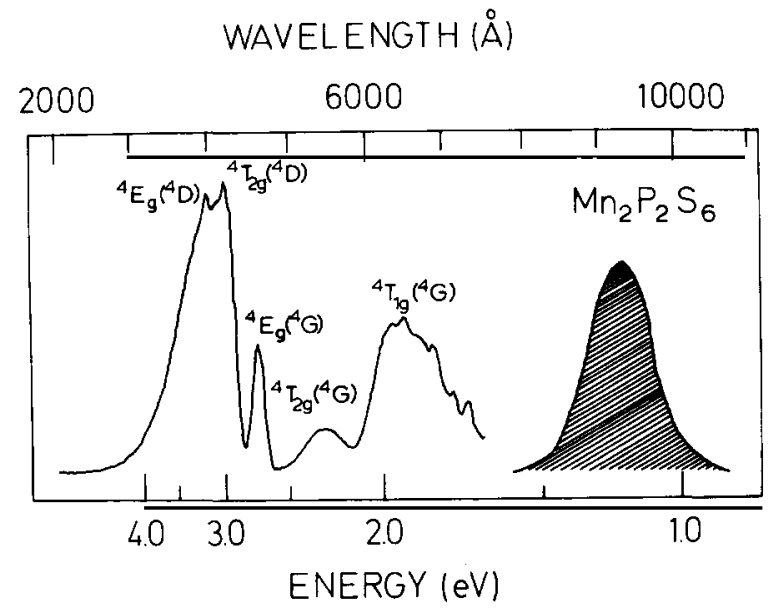

Fig. 3. Photoexcitation and photoluminescence spectra of $\mathrm{Mn}_{2} \mathrm{P}_{2} \mathrm{~S}_{6}$ recorded at $77 \mathrm{~K}$.

in fig. 2b. Essentially identical absorption edge curves were obtained for $\mathrm{Zn}_{2} \mathrm{P}_{2} \mathrm{~S}_{6}$ and $\mathrm{Mg}_{2} \mathrm{P}_{2} \mathrm{~S}_{6}$. Note that the lowest energy excitation band $(2.95 \mathrm{eV})$ falls just below the absorption edge in a region of weak absorption near the tail.

The photoluminescence spectrum of $\mathrm{Cd}_{2} \mathrm{P}_{2}$ $\mathrm{S}_{6}$ (pyridine) 0.5 $_{0.5}$ varied depending upon whether water was present during the intercalation process. When pyridine containing $3 \%$ by weight of water is used, the rate of intercalation is rapid and the product crystals are opaque and yellow. The excitation maximum shifts approximately $0.5 \mathrm{eV}$ to lower energy and none of the original host lattice photoluminescence bands are present. Rather a broad, photoluminescence band is observed at $1.66 \mathrm{eV}$ (fig. 2d). These spectral changes are accompanied by a tenfold increase in photoluminescence intensity and persist even after thermal deintercalation under vacuum.

When the intercalation reaction is carried out under anhydrous conditions, the rate of reaction is considerably slowed and the product crystals are clear, colorless and virtually indistinguishable in appearance from the unintercalated lattice. The excitation and photoluminescence spectra are unperturbed by the intercalation process when carried out in the absence of water.

\section{Discussion}

\section{Host lattice luminescence and excitation spectra}

The photoluminescence spectra of the $\mathrm{M}_{2} \mathrm{P}_{2} \mathrm{X}_{6}$ lattices investigated in this work are qualitatively similar to the photoluminescence spectra of the structurally related compounds $\mathrm{GaS}$ and $\mathrm{GaSe}$. The photoluminescence of the GaX lattices has been investigated intensely for more than a decade. The GaX lattices are lamellar in nature [12] and are derived from the $\mathrm{M}_{2} \mathrm{P}_{2} \mathrm{X}_{6}$ lattice by replacing both the transition metal ions and the $\mathrm{P}_{2}$ pairs with $\mathrm{Ga}_{2}$ atom pairs and changing the sulfur coordination geometry from octahedral to trigonal bipyramidal. The electronic band structures of the $\mathrm{M}_{2} \mathrm{P}_{2} \mathrm{X}_{6}$ and $\mathrm{GaX}$ lattices are very similar and have been compared by Piacentini et al. [8].

$\mathrm{GaS}$ is an indirect band-gap semiconductor. The band structure of the hexagonal (beta) polytype of GaS has been calculated by Schlüter [13]. The direct-gap absorption spectrum of $\mathrm{GaS}$ begins at about $3 \mathrm{eV}$. The photoluminescence spectrum [14-17], which is believed to originate from the indirect band at $2.59 \mathrm{eV}$, extends from about $2.6 \mathrm{eV}$ to below $1.8 \mathrm{eV}$ and consists of a high-energy, structured photoluminescence between $2.6-2.5 \mathrm{eV}$, a broad structureless band at $2.45 \mathrm{eV}$ and a weaker broad feature at $2.15 \mathrm{eV}$. The sharp high-energy photoluminescence is strongly sample dependent and is due to indirect band-gap, freeexciton emission. The remaining features have been identified unambiguously with localized donoracceptor recombination photoluminescence [18].

The spectral behavior of $\mathrm{GaS}$ is closely reproduced in the $\mathrm{M}_{2} \mathrm{P}_{2} \mathrm{~S}_{6}$ lattices. Thus, the first sharp feature in the absorption spectrum of $\mathrm{GaS}$ at ca. $3 \mathrm{eV}$ corresponds closely to the energy of the first band in the excitation spectrum of the $\mathrm{M}_{2} \mathrm{P}_{2} \mathrm{~S}_{6}$ lattices investigated in this work. This feature is assigned to the $\mathrm{Ga}_{2}$ and $\mathrm{P}_{2}$ antibonding $\leftrightarrow$ bonding transition in the respective compounds. All of the lattices investigated possess this feature in the excitation spectrum at approximately the same energy. This assignment is consistent with both the expected energy of this transition, the weakness in direct absorption and the narrowness of the electronic band [4]. Moreover, 
the transition is strongly polarized along the direction of the $\mathrm{P}_{2}$ bond which is normal to the basal plane. The direct absorption spectrum was recorded at normal incidence, which would prohibit observation of the $\mathrm{P}_{2}$ anti-bonding $\leftarrow$ bonding transition. Essentially identical polarization behavior is observed for the equivalent transition in $\mathrm{GaS}$ and GaSe [19]. Bourdon and Khelladi [20] have observed enhanced absorption at oblique incidence when the electric field of the incident radiation had a component parallel to the stacking axis.

The high-energy photoluminescence peak of $\mathrm{Cd}_{2} \mathrm{P}_{2} \mathrm{~S}_{6}$ at $2.4 \mathrm{eV}$ may be compared to the first emission band in $\mathrm{GaS}$ which originates from the indirect band [18]. The gap $(0.6 \mathrm{eV})$ between the highest energy photoluminescence band and the first absorption feature would then correspond to the separation between the direct and indirect band gaps as in $\mathrm{GaS}(0.4 \mathrm{eV})$. The band gaps in these two materials are expected to be nearly identical. Finally, the photoluminescence spectra of the $\mathrm{M}_{2} \mathrm{P}_{2} \mathrm{~S}_{6}$ lattices also exhibit broad maxima $(2.11 \mathrm{eV}, 1.5 \mathrm{eV})$ depending upon crystal history, temperature and wavelength of excitation. The similarity of the $\mathrm{M}_{2} \mathrm{P}_{2} \mathrm{X}_{6}$ photoluminescence spectra to that of GaS suggests that the multiple photoluminescence bands are due to donoracceptor recombination photoluminescence. However, considerably more studies of the type preformed on $\mathrm{GaS}$ would be required to confirm this supposition.

$\mathrm{Mn}_{2} \mathrm{P}_{2} \mathrm{~S}_{6}$ does not exhibit either $\mathrm{C} \rightarrow \mathrm{V}$ or recombination photoluminescence. Rather, $\mathrm{Mn}(\mathrm{II})$ $\mathrm{d} \rightarrow \mathrm{d}$ emission $\left({ }^{4} \mathrm{~T}_{1 \mathrm{~g}} \rightarrow{ }^{6} \mathrm{~A}_{1 \mathrm{~g}}\right)$ is observed [10]. The $3 \mathrm{~d}$ orbitals of $\mathrm{Mn}$ fall in the band gap and evidently quench the band-edge photoluminescence. Similar behavior has been observed when $\mathrm{Mn}$ (II) is doped into GaSe [20]. Mn d $\rightarrow \mathrm{d}$ photoluminescence can be stimulated either by direct excitation of $\mathrm{d} \leftarrow \mathrm{d}\left({ }^{2} \mathrm{E}_{1 \mathrm{~g}},{ }^{2} \mathrm{~A}_{1 \mathrm{~g}},{ }^{4} \mathrm{~T}_{1 \mathrm{~g}},{ }^{4} \mathrm{~T}_{2 \mathrm{~g}} \leftarrow{ }^{6} \mathrm{~A}_{1}\right)$ transitions lying below the main band edge, or by excitation into the phosphorus anti-bonding state. This suggests some overlap of the metal $\mathrm{d}$ and phosphorus $p$ orbitals in agreement with the conclusions of previous workers [8]. Mn $d \rightarrow d$ photoluminescence was also observed from dilute $\left(10^{18} / \mathrm{cm}^{3}\right)$ Mn centers in $\mathrm{Cd}_{2} \mathrm{P}_{2} \mathrm{~S}_{6}$ when the $\mathrm{P}_{2}$ anti-bonding $\leftarrow$ bonding transition is excited [10]. Therefore, some exciton migration occurs within the phosphorus anti-bonding band to the Mn quenching centers.

There are no features observed in the excitation spectrum of $\mathrm{Mn}_{2} \mathrm{P}_{2} \mathrm{~S}_{6}$ that can be attributed to $\mathrm{d} \leftarrow \mathrm{V}$ or $\mathrm{C} \leftarrow \mathrm{d}$ charge transfer transitions. This does not necessarily imply an absence of such transitions in the direct absorption spectrum. Indeed, Piacentini et al. $[7,8]$ have identified intense features in the spectrum of $\mathrm{Ni}_{2} \mathrm{P}_{2} \mathrm{~S}_{6}$ and $\mathrm{Fe}_{2} \mathrm{P}_{2} \mathrm{~S}_{6}$ associated with charge transfer transitions of this type. It does indicate, however, that such transitions, if present, do not produce $\mathrm{d} \rightarrow \mathrm{d}$ photoluminescence. The photoexcitation spectrum of $\mathrm{Mn}_{2} \mathrm{P}_{2} \mathrm{~S}_{6}$ below the main absorption edge at $3 \mathrm{eV}$ may be analyzed entirely in terms of $\mathrm{d} \leftarrow \mathrm{d}$ transitions with a crystal field splitting parameter of $10 D q=8750 \mathrm{~cm}^{-1}$ [10], indicative of a relatively strong ligand field interaction.

Intercalated lattice photoluminescence and excitation spectra

When $\mathrm{Cd}_{2} \mathrm{P}_{2} \mathrm{~S}_{6}$ is intercalated with pyridine containing even small amounts of water, the photoluminescence and excitation spectra of the host lattice are dramatically altered. The first excitation peak is located at ca. $2.6 \mathrm{eV}$, or $0.4 \mathrm{eV}$ to lower energy of that in the host lattice. The observed shift in the excitation edge is too large to be explained solely in terms of changes in interlayer interactions. The spectral changes persist even after thermal deintercalation at room temperature in high-vacuum. The position of the excitation band is close to the indirect band edge.

It has been previously demonstrated [3] that amine intercalation of transition metal dichalcogenides perturbs the electronic band structure in a variety of ways, including broadening of the conduction and valence bands so that the band edges extend into the band gap, shifting the Fermi energy through charge transfer to the lattice and formation of charge transfer complexes between the intercalate and the host lattice. For example, a $0.6 \mathrm{eV}$ red shift in the $2.8 \mathrm{eV}$ absorption edge of $1 \mathrm{~T}-\mathrm{HfS}_{2}$ is caused by intercalation with cyclopropylamine. In addition, a new band attributed 
to a charge transfer excitation is introduced $1.2 \mathrm{eV}$ below the original absorption edge [21].

ESR studies of pyridine intercalated $\mathrm{Cd}_{2} \mathrm{P}_{2} \mathrm{~S}_{6}$ [22] indicate that substantial lattice disorder results from a single intercalation-deintercalation cycle. This is consistent with EXAFS measurements on metallocene intercalated $\mathrm{Mn}_{2} \mathrm{P}_{2} \mathrm{~S}_{6}$ [23] which have shown that intercalation introduces disorder into the $\mathrm{Mn}-\mathrm{S}$ and $\mathrm{Mn}-\mathrm{Mn}$ bond distances. The RMS distortion amplitudes are typically $0.05 \AA$ for the $\mathrm{M}-\mathrm{S}$ bonds and $0.10 \AA$ for the $\mathrm{Mn}-\mathrm{Mn}$ bonds [24].

States introduced below the conduction band edge have increasingly localized character as they fall deeper within the band gap. The increase in the intensity of photoluminescence may result directly from an increase in the density of such states upon intercalation. The shift of the photoluminescence peaks to lower energy suggests that more states are created deeper within the band gap.

When $\mathrm{Cd}_{2} \mathrm{P}_{2} \mathrm{~S}_{6}$ is intercalated with pyridine under anhydrous conditions, the excitation spectrum, absorption edge and the photoluminescence spectrum remain virtually unperturbed. This observation suggests that the electronic band structure of these materials is determined dominantly by two-dimensional intraplanar interactions and is little affected by interplanar interactions. Moreover, the intercalation of pyridine does not significantly affect the two-dimensional band structure of the material, nor does pyridine create characteristic defects in the lattice which might serve as trapping sights for the mobile excitons present in these materials. Neither does the pyridine affect the position of the fermi energy in these materials through donation of charge to the host lattice.

\section{Conclusion}

Ultraviolet photoexcitation spectroscopy of the $\mathrm{M}_{2} \mathrm{P}_{2} \mathrm{~S}_{6}$ lattices results in a considerable simplification of the electronic spectrum as a result of suppressing absorption bands which do produce photoluminescence. By selectively monitoring either transition metal or band-edge photoluminescence, it has been possible to gain some insight to the origin and probable assignment of certain features of the direct transmission spectrum.

Analysis of the ultraviolet photoexcitation spectra of several $\mathbf{M}_{2} \mathbf{P}_{2} \mathrm{~S}_{6}$ compounds indicates that all exhibit a narrow (FWHM $<0.5 \mathrm{eV}$ ) band $\leftrightarrow$ band transition at ca. $3 \mathrm{eV}$ on the absorption edge of the main $\mathrm{C} \leftrightarrow \mathrm{V}$ transition. This band is assigned to the $P_{2}$ pair anti-bonding $\leftarrow$ bonding transition that is predicted by the electronic band model for these materials to lie near the position observed experimentally.

Excitation and photoluminescence spectroscopy of pyridine intercalated $\mathrm{Cd}_{2} \mathrm{P}_{2} \mathrm{~S}_{6}$ indicate that small amounts of water, when present during the intercalation process, results in irreversible changes to the host lattice electronic band structure. Pyridine $/ \mathrm{H}_{2} \mathrm{O}$ intercalation of these layered lattices intensifies the band-edge photoluminescence and results in a ca. $0.4 \mathrm{eV}$ shift to lower energy. This behavior is consistent with the broadening of the conduction band edge into the band gap or the activation of the forbidden indirect band-gap transition. In the absence of water, pyridine intercalation does not substantially affect the electronic structure of the lattice.

\section{Acknowledgement}

This work was supported by grants from the Petroleum Research Fund (16317-AC5-C) and the National Science Foundation (CHE 8200857).

\section{References}

[1] W. Klingen, G. Eulenberger and H. Hahn, Z. Anorg. Allg. Chem. 401 (1973) 97.

[2] B.E. Taylor, J. Steger and A. Wold, J. Solid State Chem. 7 (1973) 461.

[3] S.S.P. Parkin and S.C. Bayliss, J. Phys. C: Solid State Phys. 15 (1982) 6851-6856.

[4] F.S. Khumalo and H.P. Hughes, Phys, Rev. B 23 (1981) 5375-5383.

[5] R. Brec, D.M. Schleich, G. Ouvrard, A. Louisy and J. Rouxel, Inorg. Chem. 18 (1979) 1814-1818.

[6] J.P. Audiere, R. Clement, Y. Mathey and C. Mazieres, Physica 99B (1980) 133-135.

[7] M. Piacentini, F.S. Khumalo, C.G. Olson, J.W. Anderegg and D.W. Lynch, Chem. Phys. 65 (1982) 289-304. 
[8] M. Piacentini, F.S. Khumalo, G. Leveque, C.G. Olson and D.W. Lynch, Chem. Phys. 72 (1982) 61-71.

[9] M. Piacentini, V. Grasso, S. Santangelo, M. Fanfoni, S. Modesti and A. Savoia, Nuovo Cimento D 4 (1984) 444.

[10] J. Boerio-Goates, E. Lifshitz and A.H. Francis, Inorg. Chem. 20 (1981) 3019-3023.

[11] E. Lifshitz and A.H. Francis, J. Phys. Chem. 86 (1982) $4715-4718$.

[12] Z.S. Basinski, D.B. Dove and E. Mooser, Helv. Phys. Acta 34 (1961) 373.

[13] M. Schlüter, Nuovo Cimento B 13 (1973) 313.

[14] M. Springford, Proc. Phys. Soc. 82 (1963) 1020

[15] G.A. Akhundov, G.M. Gasumov and F.I. Ismailov, Opt. Spectry 26 (1969) 351.

[16] A. Cingolani, A. Minafra, P. Tantalo and C. Paorici, Phys. Status Solidi (a) 4 (1971) K83.
[17] A. Mercier, E. Mooser and J.P. Voitchovsky, J. Lumin. 7 (1973) 241.

[18] B.C. Cavenett, Adv. Phys. 30 (1981) 475-538.

[19] F. LeToullee, N. Piccioli, M. Mejatty and M. Balkanski, Nuovo Cimento B 38 (1977) 159.

[20] A. Bourdon, F. Khelladi, Solid State Commun. 9 (1971) 1715.

[21] S.S. Ishchenko, S.M. Okulov, G.B. Abdullaev, G.L. Belen'kji, V.G. Grachev, M.F. Deigen, R.Kh. Nani, E. Yu. Salaev and Yu.G. Semenov, Sov. Phys. Solid State 17 (1975) 1168.

[22] E. Lifshitz, A.E. Gentry and A.H. Francis, J. Phys. Chem. 88 (1984) 3038.

[23] M. Michalowicz and R. Clement, Inorg. Chem. 21 (1982) 3872. 